\title{
Müller cyst: report of a case in pregnancy
}

\author{
Raúl D. Lara ${ }^{1 *}$, Junior J. Araiza1, Tecaztipocla E. López ${ }^{2}$, Maria del R. Garay ${ }^{3}$, \\ Maria I. Tolentino ${ }^{3}$, Jorge A. Barbabosa ${ }^{3}$
}

\begin{abstract}
${ }^{1}$ Department of Gynecology and Obstetrics, ${ }^{2}$ Department of Radiology, Resident at the Postgraduate School of Naval Sanity, Universidad Naval and the Hospital General Naval de Alta Especialidad, Secretaría de Marina Armada de México, SEMAR.

${ }^{3}$ Gynecology-Obstetrics Service of the Hospital General Naval de Alta Especialidad, Secretaría de Marina Armada de México, SEMAR.
\end{abstract}

Received: 03 May 2018

Revised: 17 June 2018

Accepted: 23 June 2018

\section{*Correspondence:}

Dr. Raúl D. Lara,

E-mail: danievan0910@gmail.com

Copyright: (C) the author(s), publisher and licensee Medip Academy. This is an open-access article distributed under the terms of the Creative Commons Attribution Non-Commercial License, which permits unrestricted non-commercial use, distribution, and reproduction in any medium, provided the original work is properly cited.

\begin{abstract}
Müller cysts are alterations in the development of sexual cords and remain as malformations associated with them. They can occur in many morphological varieties. In the case of pregnancy, vaginal tumors can complicate labor because they cause obstruc-tion of the canal. During labor, these alterations can complicate the diagnosis and proper management of pregnancy. A 22-year-old female, who came to the hospital at 30.1 weeks of gestation for the first time, due to obstetric pain, vaginal tumor was detected, the patient triggered preterm labor, which did not address medical management based on oral and intravenous uteroinhibitors, so a cesarean is decided, later in the puerperium magnetic resonance was performed finding a defect in the vaginal wall, compatible with probable Müller's cyst. Due to its low frequency but high impact on pregnancy, vaginal tumors are a diagnostic and therapeutic challenge, due to their embryological origin should be detected and advise on the consequences of them. As a result, some other alterations may coexist, which is why complementary studies are essential. In the pregnancy protocol, the proper location of the cysts guides us to a specific embryological origin, as well as a preventive intervention can be planned in cases like this. If these patients are asymptomatic, surgical intervention is not required, much less during pregnancy unless an obstetric indication for interruption is determined.
\end{abstract}

Keywords: Müller's cyst, Preterm birth, Pregnancy, Vaginal cyst

\section{INTRODUCTION}

Müller cysts are tumors that are created from the remnants of the sexual ducts of Müller, these may be visible in imaging studies, physical or surgical explorations. $^{1}$ Present up to $2-4 \%$ of the female population. ${ }^{2}$

Phenotypic sexual differentiation, especially during the formation of the vulvovaginal and Müllerian systems is determined by genetic (46XX), gonadal and hormonal influences. To mention some associated hereditary alterations: camptobrachydactyly, hand-foot-genital, McKusick-Kaufman, Johanson-Blizzard, anomalies, renal-genital-middle ear, Fraser syndrome, uterine hernia syndrome, Mayer-Rokitansky-Küster syndrome- Hauser.

Even if their differentiation is interrupted early because of their interaction with the paramesonephric and metanephric systems they may coexist with renal alterations. Treatments based on puncture and aspiration with instillation of $5 \%$ tetracycline and povidone iodine 
have been described. Vaginal surgical approaches have also been proposed in these cases due to their location, as well as removal of the tumor in its entirety and vaginoplasty. ${ }^{3,4}$

\section{CASE REPORT}

Authors present the case of a 22-year-old patient with a 13-year history of menarche, regular menstrual cycles, beginning of sexual life 18 years, 2 sexual partners, no previous pap smear, pregnancy 1 , pregnancy 30.1 weeks per date of last menstruation type I, which comes for the first time with pregnancy of 30.1 weeks of gestation with obstetric type pain, without previous prenatal control.

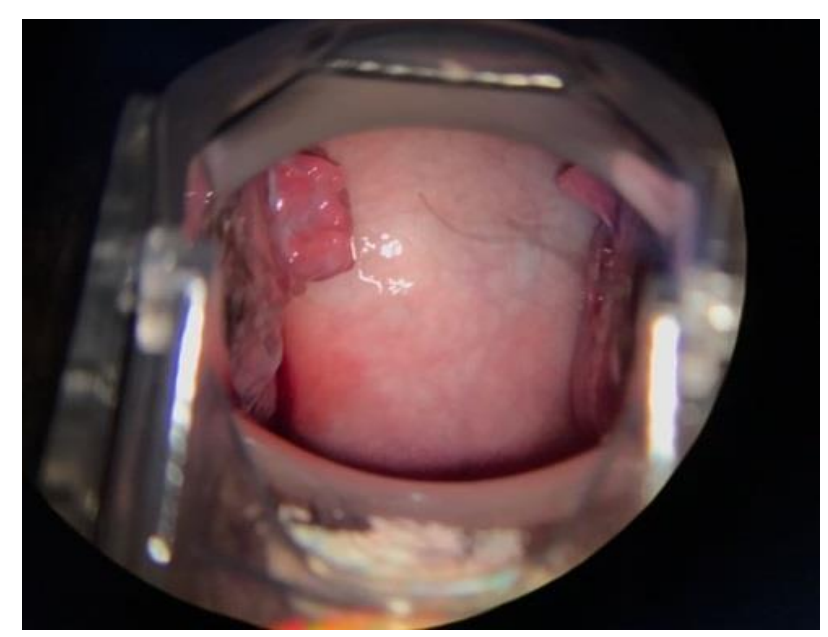

Figure 1: Tumor in the vaginal canal in a female patient at 30.1 weeks of gestation.

Physical examination revealed a $23-\mathrm{cm}$ uterine fundus, palpable regular uterine activity, 3 contractions in 10 minutes, a fetal heart rate of 145 beats per minute, cephalic, free, to the vaginal touch with the presence of a tumor in the vaginal canal (Figure 1) approximate dilation of $2 \mathrm{~cm}$, speculoscopy is performed, finding protrusion of trans-parent membranes, normal rest.

Start protocol of preterm delivery, uteroinhibition, is started, being satisfactory. Complementary studies are requested. Laboratories: gluc 78, creates 0.46 , c-reactive protein $0.41 \mathrm{mg} / \mathrm{dl}$, cortisol $18.58 \mathrm{mcg} / \mathrm{dl}$, leu $11.6 \mathrm{mil}$, hb $12.6 \mathrm{~g} / \mathrm{dl}$, hct $36 \%$, plaq $236 \mathrm{mil}$, neu $71.6 \%$, neu \# 8.3 , lymph $22.1 \%$, linf \# 2.6, mon \#0.6, vsg $24 \mathrm{~mm} / \mathrm{hr}$. Ego: scarce bacte-ria, scant yeast, leucos 3-5 per field, tp 13.8, inr 1.026, ttp 28, ac. Uric acid $3.1 \mathrm{mg} / \mathrm{dL}, \mathrm{Na} 137$ mmol / 1, CCl 107, mmol / L, co2 20.4, K $3.52 \mathrm{mmol} / \mathrm{L}$, negative urine cultures. Ultrasound is requested Figure 2.

Continues in hospitalization with adequate fetal growth, with treatment for urinary tract infection, pulmonary maturity schemes, absolute rest, thromboprophylaxis, triggering at 30.2 weeks of gestation preterm labor that does not seat intravenous uteroinhibition with progression of modifications cervical to $6 \mathrm{~cm}$, so an emergency caesarean section is performed, a product is obtained that breathes and cries at birth without apparent alterations.

Subsequently, magnetic resonance imaging was decided to improve the diagnostic impression of the tumor (Figure 3 and 4).

In the follow-up clinic at 2 weeks, the patient was asymptomatic, without abdominal pain, without urinary symptomatology, by speculoscopy with vaginal cysts after cesarean section only with a partial decrease in size, as well as the insertion of the vaginal cyst in the left anterolateral wall of the vagina in its proximal third, which is determined by clinical and Müller's defect image of the Muller cyst type 5. Continuous ambulatory monitoring.

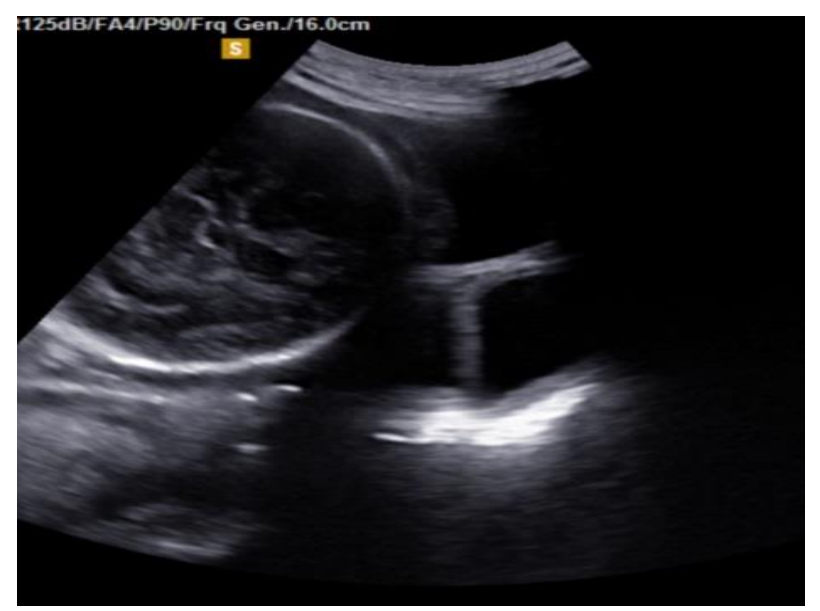

Figure 2: Abdominal ultrasound is observed in the vaginal canal defined edge tumor, anechoic, homogeneous, pregnancy of 31.6 weeks of gestation by average fetome, product with fcf $145 \mathrm{bpm}$, average fetome for 1761 grams, amniotic fluid per phelan of 9.

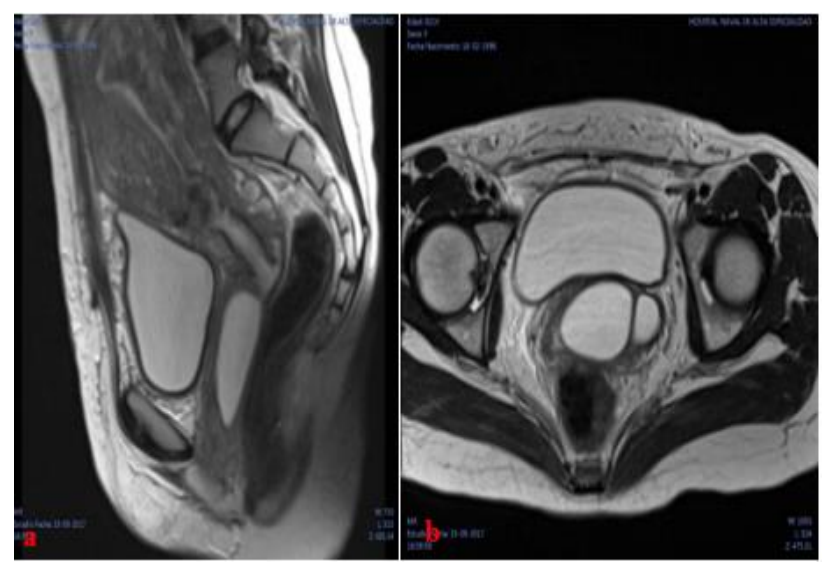

Figure 3 (a and b): Intravaginal cyst that communicates and continues with a duct less than 1 $\mathrm{cm}$ in diameter that remains adjacent to the right ureter, up to the ipsilateral renal hilum that corresponds to the probable remnant of the mesonephric duct. 


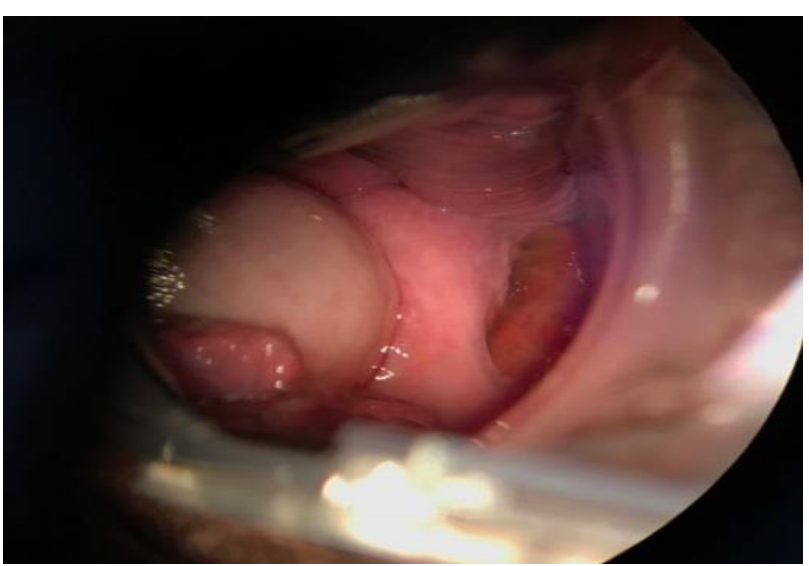

Figure 4: Tumor of soft, soft consistency, dependent on left anterolateral vaginal wall that fills $90 \%$ of the vaginal canal, not painful, not tense, without changes with respect to previous assessment.

\section{DISCUSSION}

Müller's defects occur in up to $2-4 \%$ of the female population. With a history of abortions and infertility, their incidence increases 5-10\%, 5-10\% with recurrent miscarriages, $25 \%$ of late abortions or preterm delivery have Müllerian defects. Vaginal cystic masses have been reported for most of Müllerian origin in the anterior wall of the vagina during the second trimester of gestation and were originally diagnosed as cystocele. ${ }^{2}$ Its manifestation can vary from a late menarche, sensation of vaginal bulge, with partial or complete obstruction of the outflow tract, pelvic pain, are usually asymptomatic until they present a miscarriage or premature delivery. ${ }^{1}$ The most frequent location of vaginal cysts of Müllerian origin are usually detected mostly in the anterolateral wall of the vagina. $^{2}$ The diagnosis of these anterior vaginal wall masses is more accurately reported with an MRI and urethrocystoscopy, although initially transvaginal ultrasound is the most reliable. Among the differential diagnoses in this location are Gartner cysts, urethral diverticulum, emphysematous vaginitis, dermoid cyst. ${ }^{2}$ When the Müller-derived cyst grows a lot it can distend the introitus, protruding into the vaginal canal, with dome morphology, the thin epithelium that covers it gives a translucent appearance, the palpation mass is usually tense and fluctuates, they may be $1-7 \mathrm{~cm}$ in diameter, these cysts usually have paramesonephric or mucinous columnar epithelium, although they may have any tissue of Müllerian, endocervical, endometrial or Fallopian origin. ${ }^{4,5}$ The indication of surgical treatment is presented if they are large and symptomatic. ${ }^{5}$ In this situation the preterm labor had an indication of cesarean section due to vaginal obstruction and premature labor. ${ }^{6}$ The risk of torsion of a vaginal cyst independent of the origin is around $5 \% .^{7}$ In case of presenting some type of malignant degeneration these tumors require if they meet criteria of malignancy, cytology and biopsy to assess pregnancy resolution and subsequent surgical treatment depending on the quarter in which it is diagnosed. ${ }^{8}$ Pregnancy care must continue according to the obstetric condition and the birth path, around triggering a premature delivery should take appropriate preventive measures to reduce the risk of the product. ${ }^{9,10}$ Renal anomalies can occur up to $30-40 \%$ and skeletal abnormalities up to $15 \%$ of patients, renal agenesis in $10-15 \%$ of patients with Müllerian anomalies, $5-8 \%$ have abnormal karyotypes, present 46XY normal female karyotype in a general way. ${ }^{11,12}$ Müller's anomalies are classified as obstructive rather than obstrictive. ${ }^{13}$ The presence of hematometrocolpos is a consequence of the obstruction of the menstrual flow in the vagina. ${ }^{14}$ Studies have been presented where these malformations are associated with cervical incompetence, however it occurs more frequently in the bicornuate uterus, as well as other anomalies of the fetal statics such as transverse situation, breech presentation, cephalic malposition. ${ }^{15,16}$

\section{CONCLUSION}

Due to its low frequency but high impact on pregnancy, vaginal tumors are a diagnostic and therapeutic challenge. Because of their embryological origin, they should be detected and advised on their consequences. As a result, some other alterations may coexist, which is why complementary studies are essential. In the pregnancy protocol, the proper location of the cysts guides us to a specific embryological origin, as well as a preventive intervention can be planned in cases like this. These conditions can be mostly benign, however the clinic will guide us to rule out a tumor with potential malignant degeneration.

If these patients are asymptomatic, surgical intervention is not required, much less dur-ing pregnancy unless an obstetric indication for interruption is determined.

Funding: No funding sources Conflict of interest: None declared

Ethical approval: Not required

\section{REFERENCES}

1. Grindler NM, Cooper AR. Vulvovaginal and Müllerian anomalies [Internet]. 20 ${ }^{\text {th }}$ Ed. Nelson. Treaty of pediatrics. Elsevier Espa;2018:1-50

2. Macías, N.N, Velázquez, P.I, Godoy, N. Gartner's duct cyst. Case report and literature review. Ginecol Obstet Mex. 2014; 82 (82): 252-6.

3. Eilber KS, Raz S. Benign cystic lesions of the vagina: a literature review. J Urol. 2003;170(3):71722.

4. Montero Sánchez M, Prada Arias M, Muguerza Vellibre R, Sousa Roucoy C, Rodrí-guez A. A vaginal tumor of prenatal diagnosis. An Pediatr. 2008;6 (1):87-8.

5. Adauy A, Salinas H, Naranjo B, Retamales B. Vaginal Cysts. Rev Chil Obs Ginecol. 2006;71(714):252-8. 
6. Rubio-Romero JA, Ruiz-Parra AI, Martínez F, Restrepo JM, Muñoz LA, Arévalo-Rodríguez I, et al. Clinical practice guidelines for early detection of abnormalities during labor, care for normal and dystocic delivery. Rev Colomb Obstet Ginecol. 2013;64(4):379-424.

7. Bennasar, M, Fusté, P, López, M, Puerto, B, Rodríguez, D. Tumoraciones anexiales y gestación. Med Clin (Barc). 2014;1(1): 1-7.

8. Monleón J, Goberna L, Monleón FJ. Cancer and pregnancy [Internet]. Clin Res Gynecol Obstetrics 2006;33:80-92. 2006:80-92.

9. Fasgoorgar. Fasgoorgar. [Online]. Available from: http://www.fasgo.org.ar/images/PartoPrematuro.pdf [Accessed 21 July 2018].

10. Arteaga-Gómez AC, Aranda-Flores CE, MárquezAcosta G, Colín-Valenzuela A. Adnexal tumor and pregnancy: Diagnosis and treatment. Ginecol Obstet Mex. 2010;78(3):160-7.

11. Francisco JLR, Martínez C, Huerta AD. Associated with double vagina and ipsi-lateral renal agenesis. 1999;(2):616-8.

12. Fasgoorgar. Fasgoorgar. [Online]. Available at http://www.fasgo.org.ar/images/PartoPrematuro.pdf Accessed on 21 July 2018.
13. Medina SC, Aguirre FJ, Montecinos GJ, Schiappacasse FG. Pictographic re-view of the anomalies of Müllerian ducts by magnetic resonance. Rev Chil Obstet Ginecol [Internet]. 2015;80(2).

14. DPM, Zuleta JLB, Cortázar JS, Pérez M de GG. Malformation of Müllerian ducts; didelphus uterus and associated injuries. Characterization by magnetic resonance. Grup Angeles Medical Record [Internet]. 2010;8(4):223-6.

15. Savey L, Le Tohic A. Uterine malformations. EMC Ginecol [Internet]. 2003;39(4):1-18.

16. Abramovici H, Faktor JH, Pascal B. Congenital uterine malformations as indication for cervical suture (cerclage) in habitual abortion and premature deli- very. Int J Fertil. 1983;28:161-4.

Cite this article as: Lara RD, Araiza JJ, López TE, Garay MdelR, Tolentino MI, Barbabosa JA. Müller cyst: report of a case in pregnancy. Int J Reprod Contracept Obstet Gynecol 2018;7:3369-72. 